\title{
Misdiagnosis of a cloacal exstrophy variant as urorectal septum malformation in a fetus by ultrasound: A case report
}

\author{
YANG-QING XU, XIAO-HONG YANG, XIN-LIN CHEN, XIU-QIIN JI and SHENG ZHAO \\ Department of Ultrasound, Hubei Women and Children's Hospital, Wuhan, Hubei 430070, P.R. China
}

Received January 19, 2016; Accepted March 3, 2017

DOI: $10.3892 / \mathrm{etm} .2017 .4700$

\begin{abstract}
Cloacal exstrophy variants are comprised of a wide range of characteristics, of which there are four primary features, including omphalocele, bladder exstrophy, an imperforate anus and spina bifida. The existing literature regarding the differential diagnosis from alternative urinary diseases prenatally are limited. If the bladder is present, defects in the ventral wall may not be visualized with prenatal ultrasound in certain conditions, including oligohydramnios, and differential diagnosis from urorectal septum malformation sequence is a challenge. In order to improve the diagnosis of cloacal exstrophy variants, the present study investigated the misdiagnosis of a cloacal exstrophy variant as a urorectal septum malformation in a fetus by ultrasound and analyzed the reasoning of diagnosis in detail.
\end{abstract}

\section{Introduction}

Cloacal exstrophy variants comprise a wide range of disorders with four primary features: Omphalocele, bladder exstrophy, an imperforate anus and spina bifida (1). The occurrence rate of cloacal exstrophy variants is approximately 1/200,000-1/400,000 (2). No single environmental factor or genetic defect in the etiology of cloacal exstrophy has been identified $(3,4)$. Many affected pregnancies are terminated, while those that reach full term typically result in infant mortality shortly after delivery $(5,6)$. In most countries, the disease is among the most severe congenital anomalies, though increased survival rates have been observed with improvements in neonatal care and surgical technique in countries such as the USA $(7,8)$. Prenatal differential diagnosis of cloacal exstrophy from alternative urinary diseases is not well studied. If the bladder is present, defects in the ventral wall may not be visualized with prenatal ultrasound in certain conditions, including oligohydramnios, and distinguishing cloacal

Correspondence to: Dr Xiao-Hong Yang, Department of Ultrasound, Hubei Women and Children's Hospital, 745 Wuluo Road, Wuhan, Hubei 430070, P.R. China

E-mail: yangxiaohong123@163.com

Key words: cloacal exstrophy, misdiagnosis, ultrasound, case report exstrophy from urorectal septum malformation sequence (URSMS) is challenging. In order to improve the diagnosis of cloacal exstrophy, we describe the misdiagnosis of a cloacal exstrophy variant as URSMS in a fetus by ultrasound.

\section{Case report}

A 25-year-old woman (gravida, 4; para, 0; abortus, 2; ectopic, 1) was referred to Hubei Women and Children's Hospital (Wuhan, Hubei) at 26 weeks of gestation due to oligohydramnios on November 4, 2012. The patient reported vaginal bleeding that went untreated at 50 days of gestation. She was not knowingly exposed to teratogens prior to or during pregnancy and did not have a family history of congenital disease. Sonography had been performed at another hospital at 12 weeks of gestation and was normal. Conventional sonography revealed the fetus had a large of cyst located on the right kidney (size, $2.1 \times 2.0 \mathrm{~cm}$; Fig. 1) and a left hypoplastic kidney (size, $0.7 \times 0.6 \mathrm{~cm}$ ) with multiple cysts in the renal cortex (Fig. 2), dilated loops of the bowel with blind endings, vesicointestinal fistula (Fig. 3), spinal scoliosis with a tethered cord (Fig. 4), ambiguous genitalia and a lack of amniotic fluid in the fluid sac (Figs. 1-4). The bladder was visible in the pelvis (Fig. 3) and the abdominal wall appeared normal and without omphalocele. These findings suggested a diagnosis of URSMS.

A fetal blood sample was obtained via cordocentesis under ultrasonic guidance, and isolated umbilical cord blood cells were cultured for $72 \mathrm{~h}$, followed by G-banding karyotyping analysis using a Metascan Karyotyping System (Imstar S.A., Paris, France). The chromosomal phenotype was 46XY with a large Y. The family decided to terminate the pregnancy after consulting an obstetrician and pediatrician due to the poor prognosis of the abnormalities and the lack of amniotic fluid. The abortus weighed 1,110 $\mathrm{g}$ and the body was $37 \mathrm{~cm}$ long. A post-mortem examination revealed the absence of the subcutaneous muscle layer in the infra-umbilicus, through which the bowel was protruding. The abortus also exhibited an imperforate anus, a bifid scrotum without a penis and a diastasic pubic rami. Once the abdominal cavity of the abortus was opened, a dilated bowel with blind endings and vesicointestinal fistula was revealed. The jejuno-ileum and dilated colon were both reduced in length at $\sim 70$ and $\sim 10 \mathrm{~cm}$ long, respectively. Multiple cysts in the left kidney and small ureters were present. Conversely, the right kidney was enlarged and spherical-shaped. When the right kidney was opened with a 


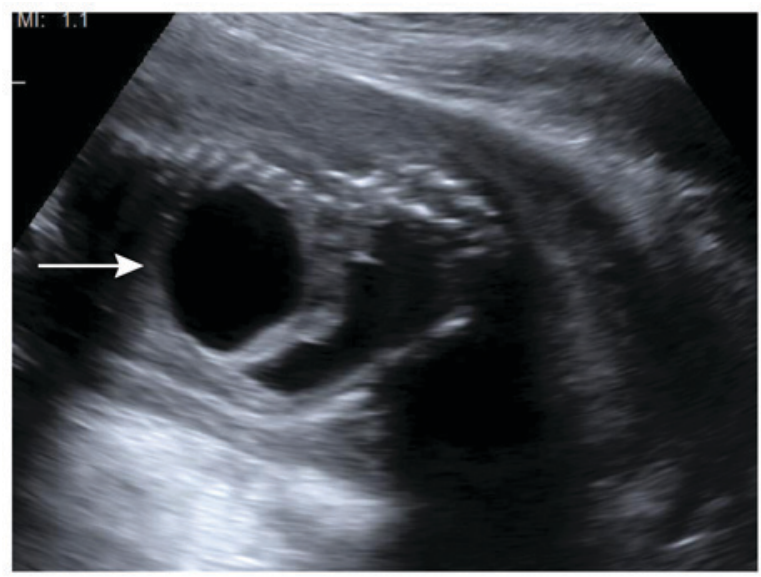

Figure 1. Sagittal view of a large cyst located on the right kidney that was $2.1 \times 2.0 \mathrm{~cm}$ in size (arrow).

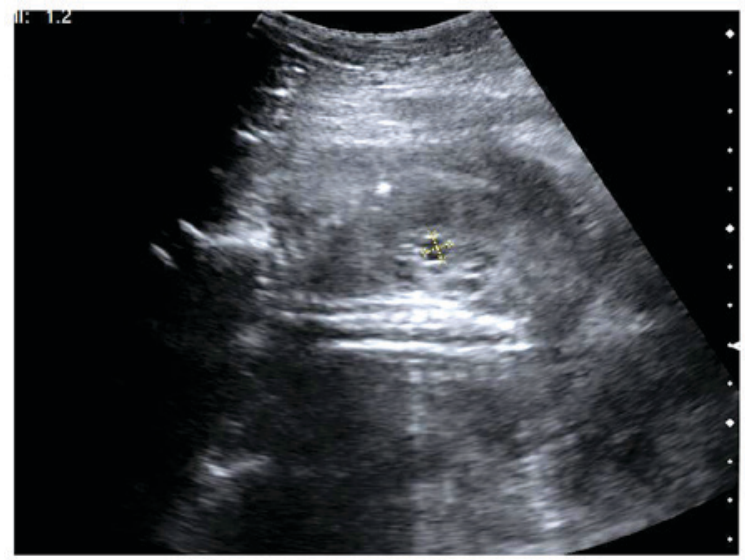

Figure 2. Sagittal view of the left hypoplastic kidney and a callipering mark demonstrating a cyst of the left hypoplastic kidney that was $0.7 \times 0.6 \mathrm{~cm}$ in size.

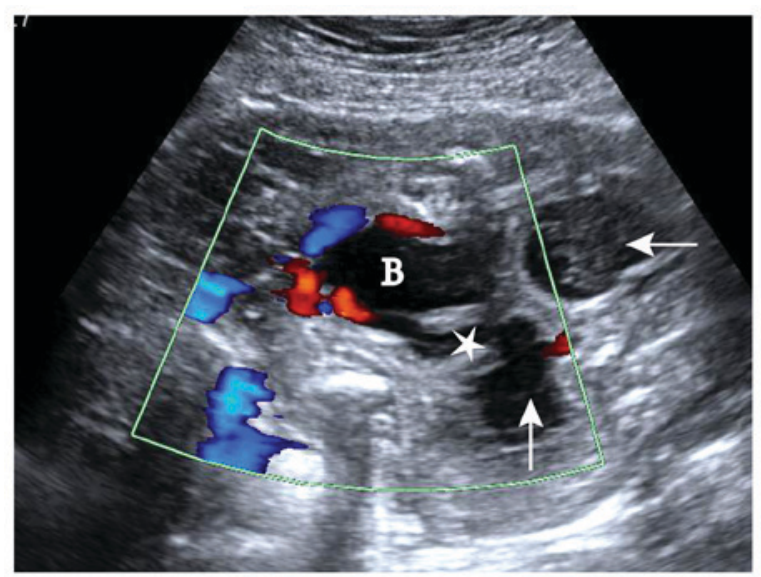

Figure 3. Transversal view of the pelvis of the umbilical artery, the filling bladder and the vesicointestinal fistula. Color flow, the two umbilical arteries around the bladder; star, vesicointestinal fistula; B, bladder; arrows, dilated intestine.

surgical knife, the cortex and medulla were visualized and a large cystic cavity filled with yellow fluid was observed laterally in the right kidney. The right ureter was contorted

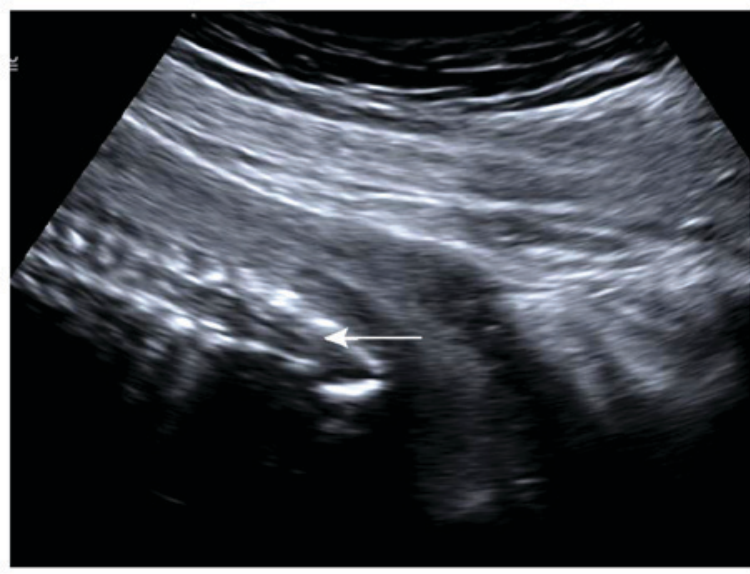

Figure 4. Longitudinal view of the spine showing the tethered spinal cord (white arrow) and the misaligned vertebrae at the extremity.

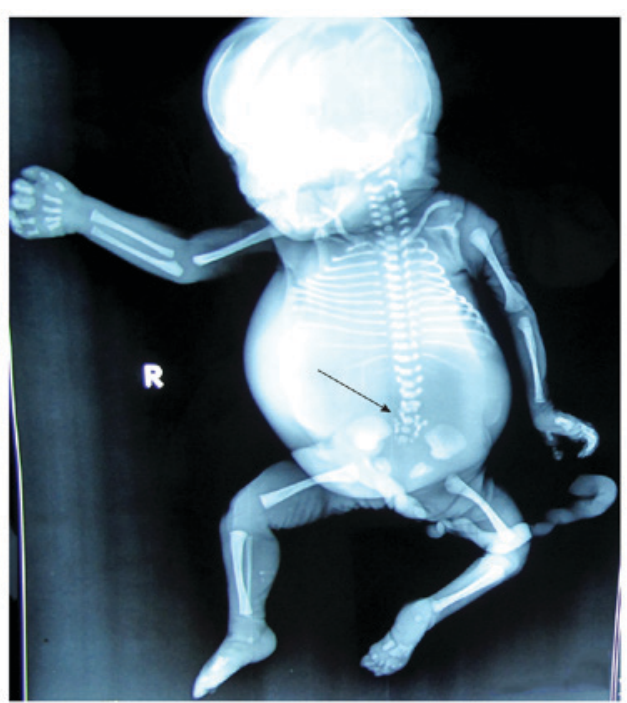

Figure 5. An X-ray photogram showing the fusion of the lumbar vertebrae 4 and 5 with three sacral vertebrae visible without coccygeal vertebrae (arrow). R, right.

and dilated. Both ureters terminated in the bladder. X-rays revealed the vertebral fusion of lumbar vertebrae 4 and 5 with three sacral vertebrae visible without coccygeal vertebrae (Fig. 5). Based on the findings from the autopsy, the diagnosis was confirmed as cloacal exstrophy variant.

All procedures performed in the present case study involving human participants were approved and in accordance with the ethical standards of The Ethics Committee of Hubei Women and Children's Hospital and with the 1964 Helsinki declaration and its later amendments or comparable ethical standards. Informed consent was obtained from the parents of the fetus in the present case study.

\section{Discussion}

The primary difference between the prenatal and postnatal findings in the present case was that the omphalocele was conspicuous through the thin membrane of skin due to the absence of subcutaneous muscle postnatally, whereas the 
omphalocele was invisible in utero. We speculated that the reason for the difference in appearance was that the high pressure outside the fetal abdominal cavity, which resulted from the lack of amniotic fluid in the amniotic sac and limited space for the fetus, prevented the bowels from protruding through the ventral abdominal wall defect. Therefore, it was difficult to diagnose the present case as a cloacal exstrophy variant based only on prenatal knowledge of a spinal defect. As a result, a misdiagnosis of URSMS was made due to the presence of defects in the internal and external genitalia without omphalocele $(9,10)$. There is widespread agreement that the infra-umbilical wall defect is the predominant difference between the two diseases as the accepted mechanism of cloacal exstrophy is the failure of the primitive streak mesoderm to extend into the infra-umbilical cloacal membrane, resulting in the incomplete formation of the lower abdominal wall and omphalocele $(11,12)$.

To the best of our knowledge, the present report presents the first description of cloacal exstrophy with no amniotic fluid. The lack of amniotic fluid may have been caused by the lack of orifices in the posterior and umbilical region. Nakano et al (13) described a case of cloacal exstrophy with normal amniotic fluid due to urachus in the umbilical region. Another possible cause for the lack of amniotic fluid may be due to the failure of fetal renal function due to the renal hypoplasia. Hendren (14) previously reported a case where the urinary system anomaly that accompanied cloacal exstrophy consisted of crossed renal ectopia, horseshoe kidneys, an ectopic ureter, ureteropelvic junction obstruction, dysplastic kidneys, megaureter and a ureterocele.

The defining characteristic observed via prenatal ultrasound and postnatal autopsy examination for the present case was a non-exstrophic bladder, which is the predominant characteristic used to distinguish cloacal exstrophy variant from classic cloacal exstrophy (15). Cloacal exstrophy involves a variety of abnormalities and to achieve a superior analysis, understanding and treatment of the disease, Manzoni et al (15) proposed a systemic classification based on their experience with 34 patients. In the study, cloacal exstrophy was divided into the following: Classic exstrophy (type I), which exhibits three subclassifications (A-C) based on the position of the exstrophic hemibladder relative to the everted bowel; and the cloacal exstrophy variant (type II), which exhibits three subclassifications (A-C) based on bladder variations, bowel variations and mixed bladder-bowel variants. According to this classification system, the present case is type IIA with a closed bladder.

In addition, the present case featured bifid scrotum and aphallia, similar to the cases reported by Nakano et al (13) and Lakshmanan et al (16). However, Lakshmanan, who is a urologic surgeon, noted that the phallus was typically located in the bladder rather than absent, a characteristic that may be observed by pathologic examination. Lakshmanan et al (16) indicated the importance for surgeons to be aware of such variations in order to prevent the inappropriate use of irrevocable measures, such as orchiectomy. Similarly, a previous study demonstrated that undivided phallic structures were shown to protrude either from the most caudal part of the exstrophic area or from the short perineum via the histopathological analysis of three cases with covered cloacal exstrophy (17). Deficiencies in the present case were the absence of pathological analysis of the vesicle tissue and the limited experience of the pathologist regarding cloacal exstrophy. Therefore, it was unknown whether the phallus was absent or present as an intravesicle phallus, as in previous cases $(17,18)$. Finally, the present results identified two testicles located laterally in the pelvic cavity via autopsy examination, which is the most common anomaly of male sexual development (19). Furthermore, Meglin et al (20) reported that 5/7 males with cloacal exstrophy were identified to exhibit cryptorchidism.

In conclusion, the present case indicated that omphalocele with the cloacal exstrophy variant could not be detected by ultrasound in utero due to the high pressure outside the abdominal cavity caused by a lack of amniotic fluid and limited space. Knowledge of this finding will aid medical practitioners to make correct prenatal diagnoses. In addition, to the best of our knowledge, the present study indicates the first reported case of a cloacal exstrophy variant without amniotic fluid in utero.

\section{References}

1. Carey JC, Greenbaum B and Hall BD: The OEIS complex (omphalocele, exstrophy, imperforate anus, spinal defects). Birth Defects Orig Artic Ser 14: 253-263, 1978.

2. Hurwitz RS, Manzoni GA, Ransley PG and Stephens FD: Cloacal exstrophy: A report of 34 cases. J Urol 138: 1060-1064, 1987.

3. Vlangos CN, Siuniak A, Ackley T, van Bokhoven H, Veltman J, Iyer R, Park JM, Keppler-Noreuil K and Keegan CE: Comprehensive genetic analysis of OEIS complex reveals no evidence for a recurrent microdeletion or duplication. Am J Med Genet A 155A: 38-49, 2011.

4. Kosaki R, Fukuhara Y, Kosuga M, Okuyama T, Kawashima N Honna T, Ueoka K and Kosaki K: OEIS complex with del(3) (q12.2q13.2). Am J Med Genet Part A 135: 224-226, 2005.

5. Mallmann MR, Reutter H, Müller AM, Geipel A, Berg C and Gembruch U: Omphalocele-exstrophy-imperforate anus-spinal defects complex: Associated malformations in 12 new cases. Fetal Diagn Ther 41: 66-70, 2017.

6. Ben-Neriah Z, Withers S, Thomas M, Toi A, Chong K, Pai A, Velscher L, Vero S, Keating S, Taylor G and Chitayat D: OEIS complex: Prenatal ultrasound and autopsy findings. Ultrasound Obstet Gynecol 29: 170-177, 2007.

7. Phillips TM, Salmasi AH, Stec A, Novak TE, Gearhart JP and Mathews RI: Urological outcomes in the omphalocele exstrophy imperforate anus spinal defects (OEIS) complex: Experience with 80 patients. J Pediatr Urol 9: 353-358, 2013.

8. Tiblad E, Wilson RD, Carr M, Flake AW, Hedrick H, Johnson MP, Bebbington MW, Mann S and Adzick NS: OEIS sequence-a rare congenital anomaly with prenatal evaluation and postnatal outcome in six cases. Prenat Diagn 28: 141-147, 2008.

9. Escobar LF, Weaver DD, Bixler D, Hodes ME and Mitchell M: Urorectal septum malformation sequence. Report of six cases and embryological analysis. Am J Dis Child 141: 1021-1024, 1987.

10. Chien JC, Chen SJ, Tiu CM, Chen YJ, Hwang B and Niu DM: Is urorectal septum malformation sequence a variant of the vertebral defects, anal atresia, tracheo-oesophageal fistula, renal defects and radial dysplasia association? Report of a case and a review of the literature. Eur J Pediatr 164: 350-354, 2005.

11. Ambrose SS and O'Brien DP III: Surgical embryology of the exstrophy-epispadias complex. Surg Clin North Am 54: 1379-1390, 1974.

12. Keppler-Noreuil KM: OEIS complex (omphalocele-exstrophyimperforate anus-spinal defects): A review of 14 cases. Am J Med Genet 99: 271-279, 2001.

13. Nakano Y, Aizawa M, Honma S and Osa Y: Completely separated scrotum and vesicointestinal fistula without exstrophy as a novel manifestation of aphallia: A case report. Urology 74: 1303-1305, 2009.

14. Hendren WH: Cloacal malformations: Experience with 105 cases. J Pediatr Surg 27: 890-901, 1992. 
15. Manzoni GA, Ransley PG and Hurwitz RS: Cloacal exstrophy and cloacal exstrophy variants: A proposed system of classification. J Urol 138: 1065-1068, 1987.

16. Lakshmanan Y, Bellin PB, Gilroy AM and Fung LC: Antenatally diagnosed cloacal exstrophy variant with intravesical phallus in a twin pregnancy. Urology 57: 1178, 2001.

17. van der Putte SC, Spliet WG and Nikkels PG: Common ('classical') and covered cloacal exstrophy: A histopathological study and a reconstruction of the pathogenesis. Pediatr Dev Pathol 11: $430-442,2008$.
18. Arunachalam P, Pillai SB and Sridhar DC: Classical cloacal exstrophy with intravesical phallus. J Pediatr Surg 47: E5-E8, 2012.

19. Phillips TM: Spectrum of cloacal exstrophy. Semin Pediatr Surg 20: 113-118, 2011.

20. Meglin AJ, Balotin RJ, Jelinek JS, Fishman EK, Jeffs RD and Ghaed V: Cloacal exstrophy: Radiologic findings in 13 patients. AJR Am J Roentgenol 155: 1267-1272, 1990. 